\title{
Paternity assurance before and after fertilization by male burying beetles (Nicrophorus quadripunctatus)
}

\author{
Mamoru Takata · Takuma Kurachi • \\ Satoshi Koyama - Toshiyuki Satoh • \\ Hajime Fugo
}

Received: 5 December 2012/ Accepted: 4 February 2013/Published online: 23 February 2013

(C) Japan Ethological Society and Springer Japan 2013

\begin{abstract}
Parental care requires a large investment of time and energy. This can reduce future parental survival and opportunities for mating. Because males are usually more uncertain of their parentage with respect to the caring of offspring than are females, the reduction in reproductive success is thought to be greater in males. Therefore, males are under selection to ensure paternity of the offspring for which they care. Males can increase paternity before and after fertilization. Before fertilization, males can increase paternity by increasing their competitive ability for fertilization. After fertilization, males can increase paternity by cannibalizing unrelated offspring. Here, we investigated the stage at which male burying beetles, Nicrophorus quadripunctatus, increase their paternity by evaluating the number of offspring sired by a nursing male in asynchronously hatched broods in relation to hatching time. We found that nursing males assure a very high level of the paternity of hatching offspring. We also found that the
\end{abstract}

\author{
M. Takata $\cdot$ H. Fugo \\ United Graduate School of Agricultural Science, \\ Tokyo University of Agriculture and Technology, \\ 3-5-8 Saiwai, Fuchu, Tokyo, Japan \\ e-mail: mamorururu2000@yahoo.co.jp \\ H. Fugo \\ e-mail: fugoh@cc.tuat.ac.jp \\ T. Kurachi $\cdot$ S. Koyama $(\bowtie) \cdot$ T. Satoh \\ Graduate School of Agriculture, Tokyo University of Agriculture \\ and Technology, 3-5-8 Saiwai, Fuchu, Tokyo, Japan \\ e-mail: skoyama@cc.tuat.ac.jp \\ T. Kurachi \\ e-mail: 50007155012@st.tuat.ac.jp \\ T. Satoh \\ e-mail: tsatoh@cc.tuat.ac.jp
}

paternity of non-nursing and nursing males remained constant across hatching time within a brood, indicating that it is unlikely that filial cannibalism plays a role in increasing the paternity of offspring. We concluded that ensuring paternity before fertilization is more important in increasing the paternity of offspring.

Keywords Nicrophorus $\cdot$ Burying beetle $\cdot$ Asynchronous hatching $\cdot$ Filial cannibalism

\section{Introduction}

Parental care is known across a range of taxa (Zeh and Smith 1985; Clutton-Brock 1991; Beck 1998; Eggert et al. 1998; Tallamy 2000; Reynolds et al. 2002; Cockburn 2006; Summers et al. 2006). Parental care requires a large investment of time and energy, which can reduce future parental survival and opportunities for mating. Because the reproductive success of males is always more limited by mating opportunities than it is for females (Bateman 1948; Wedell et al. 2006), the reduction in reproductive success by lost opportunities for future reproductions is thought to be greater in males. Furthermore, males face a greater risk of caring for unrelated offspring than females (CluttonBrock 1991; Davies 1992). Therefore, confidence of paternity for males is decreased. In a species whose females have sperm storage organs, some offspring may be fertilized by the sperm stored in a female's reproductive tract from a prior mating experience (Müller and Eggert 1989). Because investing energy and resources in unrelated offspring is costly, males are under selection to ensure the paternity of the offspring for which they care. Males can increase paternity before and after fertilization. Before fertilization, males can increase paternity by increasing 
their competitive ability for fertilization (e.g., competition for mating, mate guarding, sperm removal, and sperm competition). After fertilization, males can increase their paternity by cannibalizing some of the unrelated offspring (partial filial cannibalism). In some species, some offspring are cannibalized by their parents (reviewed by FitzGerald 1992; Manica 2002).

Filial cannibalism can be adaptive for parents to minimize parental investment. Particularly, this would applicable to filial cannibalism by females. However, the adaptive causes for filial cannibalism by males may be different from those for females, because males can decrease their parental investment by deserting a female and her offspring. Filial cannibalism by males could be adaptive if males are able to selectively cannibalize unrelated offspring.

Burying beetles, Nicrophorus spp., provide elaborate biparental care to their offspring, including provisions of food (Eggert and Müller 1997; Scott 1998). Burying beetles use the carcasses of small vertebrates as food for their larvae. Females copulate with males repeatedly and lay eggs in the soil near the carcass. In $N$. quadripunctatus, each copulatory attempt was completed within $3 \mathrm{~min}$ (Takata, unpublished study). Female burying beetles can store transferred sperm within spermatheca. In Nicrophorus vespilloides, most females already have fertile sperm stored from a previous mating when they arrive at the carcass, and some of the offspring that hatch arise from eggs fertilized by the stored sperm (Müller and Eggert 1989). The larvae hatch asynchronously over a mean time span of $25 \mathrm{~h}$ (range $4-56 \mathrm{~h}$ ) on a 15 -g carcass (in N. quadripunctatus; Takata, unpublished study). After hatching, the larvae crawl to the carcass and obtain food by begging for pre-digested carrion from their parents or by self-feeding from the carcass (in N. vespilloides: Smiseth and Moore 2002; Smiseth et al. 2003; in N. quadripunctatus: Takata, unpublished study). Partial filial cannibalism occurs in N. quadripunctatus (Takata, unpublished study). Both males and females cannibalize some of their offspring (in N. quadripunctatus: Takata, unpublished study). Previous studies on $N$. quadripunctatus have shown that offspring that hatch later face higher mortality risks when cared for by males (Takata, unpublished study). Burying beetles cannot directly recognize their relatives after the larvae have hatched (in N. vespilloides: Müller and Eggert 1990; in N. quadripunctatus: Takata, unpublished study). However, if most of the offspring fertilized by stored sperm from a previous mating hatch later, then males could increase their paternity by filial cannibalism. Here, we investigated the stage at which males increase their paternity by evaluating the number of offspring sired by a nursing male in asynchronously hatched broods in relation to hatching time.

\section{Materials and methods}

Sperm storage by females in the field

In October 2012, we collected adult female Nicrophorus quadripunctatus Kraatz in the field by using baited pitfall traps to determine the proportion of female beetles that have fertile sperm in store. Burying beetles cannot escape from the traps. Female beetles caught in the traps without conspecific males were chosen for use in this experiment. We collected 16 such females. Each female was individually placed in a plastic cup (height $8 \mathrm{~cm}$, diameter $15 \mathrm{~cm}$ ) containing $2 \mathrm{~cm}$ of moist peat and $15 \pm 0.5 \mathrm{~g}$ of carcass (a piece of fresh chicken meat). All females were given this carcass in the same state of freshness. After $93 \mathrm{~h}$, which is the approximate time when females typically finish laying eggs (Takata, unpublished study), the female and the carcass were removed from the cup. The eggs were left in the plastic cup to hatch. To determine whether the female had fertile sperm, the eggs were checked for hatching larvae at 12-h intervals. We defined reproductively active females and non-reproductive females by following the definition criteria described by Müller and Eggert (1989). A female that had laid eggs within 4 days was defined as a reproductively active female, and a female that had not was defined as a non-reproductive female. A female was considered to have fertile sperm in store if one or more larvae hatched from her eggs.

\section{Behavioural observation and maintenance of beetles}

We collected adult $N$. quadripunctatus in baited pitfall traps in Chiba, Japan, and reared the first-generation offspring in the laboratory. The beetles were maintained individually in small transparent plastic cups (height $4 \mathrm{~cm}$, diameter $6 \mathrm{~cm}$ ) at $20 \pm 1{ }^{\circ} \mathrm{C}$ under a $14: 10 \mathrm{~h}$ light:dark cycle. They were fed small pieces of fresh chicken meat twice a week. All males and females used in this experiment were sexually mature and between 21 and 35 days of age.

We used six observation groups in this study. In the first and second groups, we observed the copulation frequency of non-nursing males that were allowed to copulate with females without a carcass but did not provide parental care. We observed the copulation frequency at $1 \mathrm{~h}$ (first group) or $24 \mathrm{~h}$ (second group) following initial placement of the males with the females. Pairs of randomly selected, nonsibling, virgin male (non-nursing males) and female beetles were each placed in a plastic cup (height $8 \mathrm{~cm}$, diameter $15 \mathrm{~cm}$ ) containing $2 \mathrm{~cm}$ of moist peat. The first group was composed of 20 pairs of males and females, and the second group was composed of 30 pairs. The pairs were allowed to copulate at $20 \pm 1{ }^{\circ} \mathrm{C}$ in a dark incubator. The number of 
copulatory attempts (i.e. male mounting a female) was counted during a 30-min period at $1 \mathrm{~h}$ (first group) or $24 \mathrm{~h}$ (second group) following initial placement in the incubator.

In the third to sixth groups, we observed the copulation frequency of nursing males in different breeding periods. Females of N. quadripunctatus typically start laying eggs around $48 \mathrm{~h}$ after introduction and finish laying eggs around $84 \mathrm{~h}$ after introduction (Takata, unpublished study). We set up observation periods during pre-oviposition ( 1 and $24 \mathrm{~h}$ after introduction), oviposition (72 h after introduction), and post-oviposition (120 h after introduction). We first prepared previously mated females by following the same experimental manipulation for the first and second observation groups. The males and females were allowed to copulate for $24 \mathrm{~h}$. The females were used in the following experiment immediately after this manipulation. Pairs of randomly selected, non-sibling, virgin males (nursing males) and the previously mated female beetles were each placed in a plastic cup (height $8 \mathrm{~cm}$, diameter $15 \mathrm{~cm}$ ) containing $2 \mathrm{~cm}$ of moist peat and $15 \pm 0.5 \mathrm{~g}$ of carcass (a piece of fresh chicken meat). All pairs were given this carcass in the same state of freshness. The third group was composed of 20 pairs of males and females, and the fourth to sixth groups were composed of 42 pairs each. The pairs were allowed to copulate at $20 \pm 1^{\circ} \mathrm{C}$ in a dark incubator. The number of copulatory attempts was counted during a 30-min period at $1 \mathrm{~h}$ (third group) or $24 \mathrm{~h}$ (fourth group) or $72 \mathrm{~h}$ (fifth group) or $120 \mathrm{~h}$ (sixth group) following initial placement in the incubator. All observations were conducted under red light. Following our observations, we confirmed that all females actually did not lay eggs at 1 and $24 \mathrm{~h}$ after introduction, laid eggs at $72 \mathrm{~h}$ after introduction, and finished laying eggs before $120 \mathrm{~h}$.

Parentage analysis by using amplified fragment length polymorphism

Eleven pairs of randomly selected, non-sibling, virgin male (non-nursing male) and virgin female beetles were each placed in a plastic cup (height $8 \mathrm{~cm}$, diameter $15 \mathrm{~cm}$ ) containing $1 \mathrm{~cm}$ of moist peat. They were allowed to copulate for $24 \mathrm{~h}$ at $20 \pm 1{ }^{\circ} \mathrm{C}$ in a dark incubator. At $24 \mathrm{~h}$ following placement in the incubator, the females were placed in a new plastic cup containing $2 \mathrm{~cm}$ of moist peat and $15 \pm 0.5 \mathrm{~g}$ of carcass (a piece of fresh chicken meat) with a non-sibling, virgin male (nursing male). All pairs were given this carcass in the same state of freshness. The male, female, and carcass were removed from the cup at $93 \mathrm{~h}$, and the eggs were left in the plastic cup to hatch. The hind legs of male and female beetles were surgically removed and immediately stored in $99.5 \%$ ethanol. We collected newly hatching offspring at 4-h intervals until all the offspring had hatched and stored them in $99.5 \%$ ethanol. We obtained 248 larvae $[20.7 \pm 8.5$ larvae (mean \pm SD) from 11 clutches] and analyzed their paternity by using amplified fragment length polymorphism (AFLP). The hatching rate was $81.0 \pm 3.7 \%$ (mean $\pm \mathrm{SD}$ ).

\section{DNA extraction}

The extraction of DNA from the legs of adult beetles or the whole body of larvae was performed using a DNeasy Blood \& Tissue Kit (Qiagen, Tokyo, Japan), according to the manufacturer's instructions. Approximately $3 \mathrm{~mm}$ of the legs of the adult beetles or the whole body of larvae were transferred to a sterile $1.5-\mathrm{ml}$ microcentrifuge tube containing $180 \mu \mathrm{l}$ of ATL buffer (Qiagen) and $20 \mu \mathrm{l}$ of proteinase $\mathrm{K}$ (Qiagen) and incubated at $56{ }^{\circ} \mathrm{C}$ in a water bath to disperse the sample overnight until the tissue was completely lysed. The mixture was mixed by vortexing for $15 \mathrm{~s}$. A total of $200 \mu \mathrm{l}$ of AL buffer (Qiagen) was added to the sample and mixed thoroughly by vortexing. The mixture was then added to $200 \mu$ l of ethanol $(99.5 \%$, Wako Pure Chemical Industries, Osaka, Japan) and mixed by vortexing to yield a homogenous solution. The homogenous solution was pipetted into the DNeasy ${ }^{\circledR}$ mini column in a 2-ml collection tube and centrifuged at $8,000 \mathrm{rpm}$ for $1 \mathrm{~min}$. The DNA bound to the column was washed in two centrifugation steps by using $500 \mu \mathrm{l}$ of AW1 buffer and AW2 buffer, to improve the purity of the eluted DNA. The purified DNA was then eluted from the column in $200 \mu \mathrm{l}$ of AE buffer and stored at $4{ }^{\circ} \mathrm{C}$ until further use.

\section{AFLP procedure}

The AFLP technique was performed by following the AFLP Core Reagent Kit protocol (Invitrogen, Carlsbad, CA, USA), according to the method of Vos et al. (1995), as follows: $1 \mu$ of the total cellular DNA sample was doubledigested with $0.4 \mu \mathrm{l}$ of EcoRI/MseI (Invitrogen), $1 \mu \mathrm{l}$ of $5 \times$ reaction buffer, and $2.6 \mu \mathrm{l}$ of distilled water. Adapters specific to EcoRI and MseI digested DNA were ligated to the restriction fragments. After incubation at $37{ }^{\circ} \mathrm{C}$ for $24 \mathrm{~h}, 4.8 \mu \mathrm{l}$ of the adapter ligation mixture and $0.2 \mu \mathrm{l}$ of T4 DNA ligase (Invitrogen) were added and ligated for $2 \mathrm{~h}$ at $20{ }^{\circ} \mathrm{C}$.

\section{Pre-amplification}

The resulting products were diluted tenfold, and $10 \mu \mathrm{l}$ of reaction mixtures containing $1 \mu \mathrm{l}$ of DNA solution were used for PCR reactions in $1 \mu \mathrm{l}$ of $10 \times$ PCR buffer, $1 \mu \mathrm{l}$ of $10 \mathrm{mM}$ dNTP mix $(200 \mu \mathrm{M}$ each), $0.25 \mu \mathrm{l}$ of $10 \mu \mathrm{M}$ EcoRI (plus A) and MseI (plus C) primers, $0.05 \mu \mathrm{l}$ of TaKaRa Ex Taq (1.25 U; Takara Bio, Shiga, Japan), and 
$4.95 \mu \mathrm{l}$ of distilled water. After an initial denaturation at $95{ }^{\circ} \mathrm{C}$ for $5 \mathrm{~min}$, PCR was performed using 30 successive cycles of $94{ }^{\circ} \mathrm{C}$ for $30 \mathrm{~s}$, annealing at $56{ }^{\circ} \mathrm{C}$ for $60 \mathrm{~s}$, and $72{ }^{\circ} \mathrm{C}$ for $60 \mathrm{~s}$. Chain elongation at $72{ }^{\circ} \mathrm{C}$ was extended to 5 min after the final cycle. The PCR was performed using a PCR thermal cycler (BioRad, Richmond, CA, USA). The sequences of the primers EcoRI-A and MseI-C were $5^{\prime}$-GA CTGCGTACCAATTCA- $3^{\prime}$ and $5^{\prime}$-GATGAGTCCTGAGT AAC- $3^{\prime}$, respectively. The pre-selective amplification products were electrophoresed, and amplification was confirmed to minimise genotyping errors.

\section{Selective amplification}

The pre-selective amplification products were diluted tenfold, and $10 \mu \mathrm{l}$ of reaction mixtures containing $1 \mu \mathrm{l}$ of DNA solution were used in selective PCR amplification reactions in $1 \mu \mathrm{l}$ of $10 \times$ PCR buffer, $1 \mu \mathrm{l}$ of $10 \mathrm{mM}$ dNTP $\operatorname{mix}(200 \mu \mathrm{M}$ each), $0.05 \mu \mathrm{l}$ of $10 \mu \mathrm{M} E c o \mathrm{RI}$ (plus AGG or AAG) and $0.25 \mu \mathrm{l}$ of $10 \mu \mathrm{M} \mathrm{MseI}$ (plus CTA) primers, $0.05 \mu \mathrm{l}$ of TaKaRa Ex Taq (1.25 U), and $5.15 \mu \mathrm{l}$ of distilled water. After an initial denaturation at $95{ }^{\circ} \mathrm{C}$ for 5 min, PCR was performed using 30 successive cycles of $94{ }^{\circ} \mathrm{C}$ for $30 \mathrm{~s}$. The annealing temperature in the first cycle was $66^{\circ} \mathrm{C}$, which was subsequently reduced in each cycle by $1{ }^{\circ} \mathrm{C}$ for the next 12 cycles, and was continued at $57^{\circ} \mathrm{C}$ for $60 \mathrm{~s}$ and $72{ }^{\circ} \mathrm{C}$ for $60 \mathrm{~s}$. Chain elongation at $72{ }^{\circ} \mathrm{C}$ was extended to $5 \mathrm{~min}$ after the final cycle. PCR was performed using a PCR thermal cycler (BioRad). The sequences of the primers EcoRI-AGG, EcoRI-AAG, and MseI-CTA were 5'-GACTGCGTACCAATTCAGG-3', 5'-GACTGCGTAC CAATTCAAG-3', and 5'-GATGAGTCCTGAGTAACTA-3', respectively.

\section{Fragment analysis}

AFLPs were detected using fragment analysis with the ABI PRISM3500 system. The S500 ROX (PE Applied Biosystems, Foster City, CA, USA) fragment size standards were included in each sample. Amplified fragments with fluorescent signals were identified using GeneScan 3.2.1 (PE Applied Biosystems). All steps throughout the AFLP protocol were conducted to minimize genotyping errors.

\section{Assessment of reproducibility}

To assess the reproducibility of our AFLP data (Crawford et al. 2012), 13 samples (5.2\% of the total sample size) were replicated from the stage of restriction enzyme digestion by using the same DNA extract. The genotyping error rate in this study was $3.2 \%$ (total number of mismatched genotypes, 2; number of replicated genotypes, $63)$. The genotyping error rate was calculated, according to the method described by Pompanon et al. (2005), as the ratio of the total number of mismatched genotypes (band presence vs. band absence) to the number of replicated genotypes.

\section{Parentage analysis}

To detect paternity, all peaks were scored for presence/ absence in each individual by using the GeneScan analysis software in the 40- to 700-bp range. The presence of 2 diagnostic peaks appears to be sufficient for detecting parentage, as reported in previous studies (Questiau et al. 1999; García-González et al. 2003, 2005; Simmons et al. 2004; Suzuki et al. 2006). In the current study, for small fragments, we considered all peaks with a height above 150 fluorescent units. All fragments present in the offspring, the two potential fathers, and the mothers were scored. For paternity assignment, fragments present in larvae but absent in mothers were assumed to be derived from the father. When 1 male and a larva had 2 or more common diagnostic peaks that were absent in the other male and the mother, the former male was assigned as the father of the larva. The total number of loci obtained was 944 loci. The number of polymorphic loci retained for parentage analysis was 112 loci. We determined the paternity of $79 \%$ of the offspring, but we could not determine the paternity of the remaining offspring because they did not show any diagnostic peaks. We excluded these offspring from the following analysis.

\section{Statistical analysis}

First, one-way ANOVA was used to investigate temporal change in the frequency of copulation. The number of copulatory attempts observed in each mating period was treated as a response variable and mating periods were treated as an explanatory variable. Pairwise Wilcoxon rank sum tests were then used to examine the differences in copulation frequency between observation groups. A conservative Bonferroni adjustment for multiple testing (Zar 1984) was used for the analysis.

Second, to test the paternity bias towards non-nursing and nursing males, we compared the number of offspring sired by non-nursing males with the number of offspring sired by nursing males by using Wilcoxon rank test.

Finally, to demonstrate whether the hatching of offspring of non-nursing males was skewed towards the earlier or later hatching period, we examined the effect of hatching time on parentage distribution by using a generalized linear mixed model (GLMM) with the lme4 package (Bates and Maechler 2010). Paternity of each offspring of non-nursing or nursing males was treated as a response variable assuming a binomial distribution. 
Hatching time (i.e. the point in time when each larva hatched) was treated as an explanatory variable and family identity was treated as a random factor. All analyses were performed using R 2.12.1 GUI 1.35 (http://cran. r-project.org ). The lme4 package was used for GLMM.

\section{Results}

Sperm storage in the field

Eleven of the 16 wild-caught females were reproductively active. Nine of the 11 reproductively active females ( $82 \%)$ had fertile sperm in store. Therefore, most of the

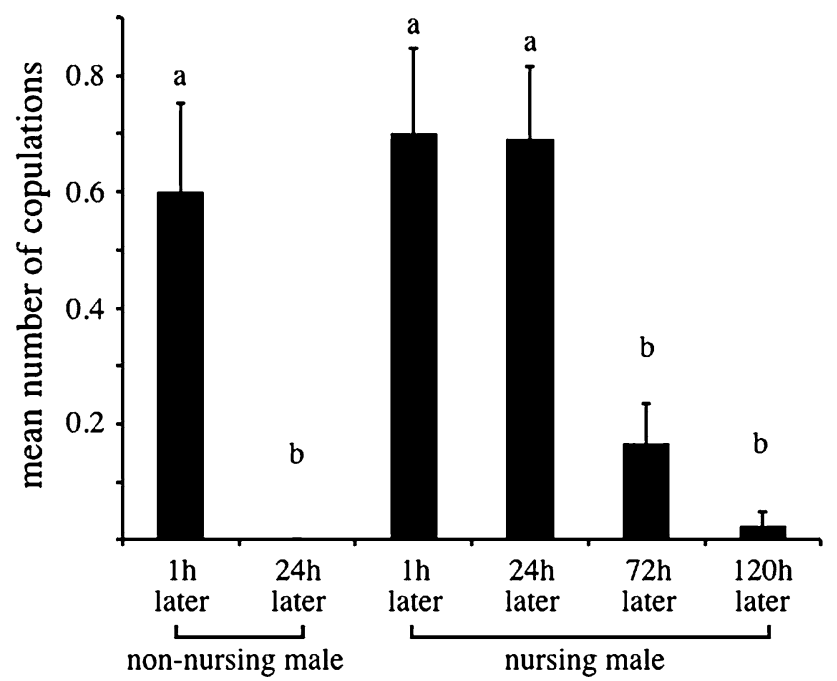

Fig. 1 Mean $( \pm \mathrm{SD})$ number of copulations by Nicrophorus quadripunctatus observed in different mating periods. The mating periods are expressed as hours after introduction of males and females. Different subscripted letters are significantly different from each other, following Bonferroni correction for multiple comparisons $(p<0.05)$ reproductively active females had stored fertile sperm in their reproductive tracts when they arrived at the carcass.

Copulatory attempts

Mating period had a significant effect on the frequency of copulation (ANOVA: $F_{5,190}=12.932, p<0.001$ ). Nonnursing males copulated with females $0.6 \pm 0.2$ times (mean \pm SD) per $30 \mathrm{~min}$ at $1 \mathrm{~h}$ after introduction (Fig. 1; Table 1). However, the number of copulatory attempts significantly decreased at $24 \mathrm{~h}$ after introduction (i.e. no copulatory attempts were observed).

Nursing males copulated with females $0.7 \pm 0.1$ times (mean $\pm \mathrm{SD}$ ) per $30 \mathrm{~min}$ at $1 \mathrm{~h}$ after introduction, and $0.7 \pm 0.1$ (mean \pm SD) times at $24 \mathrm{~h}$ following introduction (Fig. 1; Table 1). However, the number of copulatory attempts significantly decreased at $72 \mathrm{~h}(0.2 \pm 0.1$ times, mean $\pm \mathrm{SD})$ and $120 \mathrm{~h}(0.2 \pm 0.1$ times, mean $\pm \mathrm{SD})$ after introduction (Fig. 1; Table 1).

Parentage analysis

Paternity assignment to non-nursing and nursing males was biased towards the nursing male (Wilcoxon rank test, $z=-4.318, p<0.001) ; 0.4 \pm 1.2$ larvae (mean $\pm \mathrm{SD}$ ) were sired by non-nursing males and $15.8 \pm 5.7$ larvae (mean $\pm \mathrm{SD}$ ) were sired by nursing males. On average, $97 \%$ of the offspring (190/195 larvae) were sired by the nursing males. In 7/11 clutches, nursing males had $100 \%$ paternity.

Asynchronous hatching and parentage distribution

The proportion of offspring sired by nursing males was not significantly affected by hatching time (GLMM: estimate $=0.015, z=0.011, p=0.99$; Fig. 2 ); in other words, paternity of 2 groups of males remained constant across hatching time within a brood.
Table 1 Pairwise Wilcoxon rank sum tests for each of the 15 pair-wise comparisons between each mating period of nonnursing and nursing male units

Bonferroni-adjusted $p$ values are shown. Values $<0.05$ in bold are statistically significant

\begin{tabular}{llllll}
\hline & $\begin{array}{l}\text { Non-nursing male } \\
\text { 1 h later }\end{array}$ & $\begin{array}{l}\text { Non-nursing male } \\
\text { 24 h later }\end{array}$ & $\begin{array}{l}\text { Nursing male } \\
\text { 1 h later }\end{array}$ & $\begin{array}{l}\text { Nursing male } \\
\text { 24 h later }\end{array}$ & $\begin{array}{l}\text { Nursing male } \\
72 \text { h later }\end{array}$ \\
\hline $\begin{array}{l}\text { Non-nursing male } \\
24 \text { h later }\end{array}$ & $<\mathbf{0 . 0 0 1}$ & & & \\
$\begin{array}{l}\text { Nursing male } \\
1 \text { h later }\end{array}$ & 1.000 & $<\mathbf{0 . 0 0 1}$ & & \\
$\begin{array}{l}\text { Nursing male } \\
24 \text { h later }\end{array}$ & 1.000 & $\mathbf{0 . 0 0 1}$ & 1.000 & \\
$\begin{array}{l}\text { Nursing male } \\
72 \text { h later }\end{array}$ & $\mathbf{0 . 0 4 5}$ & 0.492 & $\mathbf{0 . 0 0 4}$ & $\mathbf{0 . 0 0 6}$ & \\
$\begin{array}{l}\text { Nursing male } \\
120 \text { h later }\end{array}$ & $<\mathbf{0 . 0 0 1}$ & 1.000 & & & \\
\hline
\end{tabular}




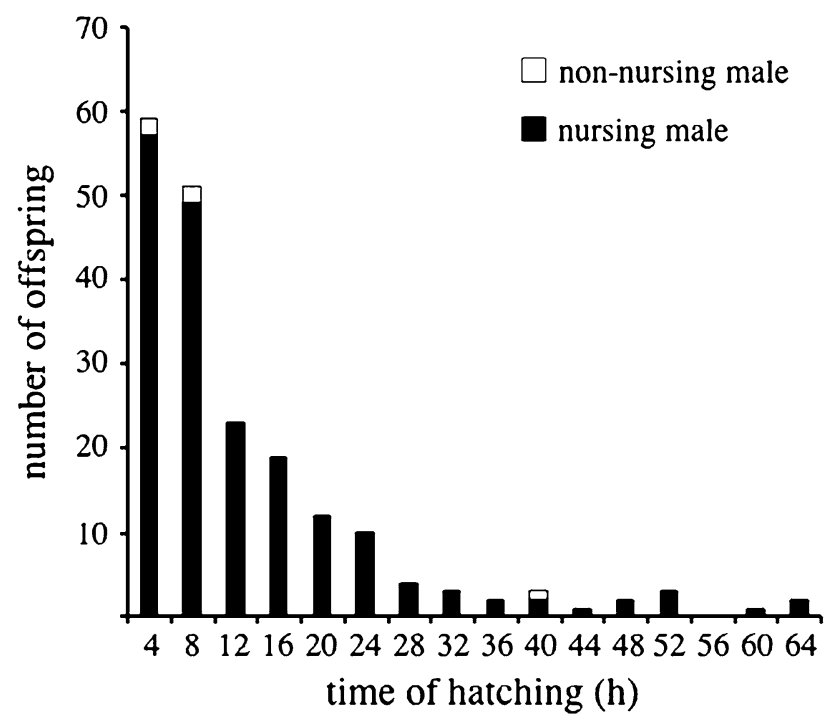

Fig. 2 Asynchronous hatching and parentage distribution. The bars denote the number of hatching larvae at 4-h intervals. The number of hatching larvae sired by non-nursing and nursing males is denoted by white and black bars, respectively

\section{Discussion}

Our study showed that majority of the offspring were sired by nursing males. We also found that the paternity of 2 groups of males remained constant across hatching time within a brood. Our study demonstrates at which stage males increase their paternity in N. quadripunctatus.

Our data shows that nursing males achieved a high level of paternity. On average, $97 \%$ of the hatching larvae were sired by nursing males. Similar results have been reported in other species of the same genus ( $N$. vespilloides: Müller and Eggert 1989; N. orbicollis: Trumbo and Fiore 1991; N. tomentosus: Scott and Williams 1993). Caring for unrelated offspring is costly for nursing males, and competition for fertilizations arises when females mate with more than one male during a single reproductive cycle (Parker 1970). In this study, most of the reproductively active, wild-caught females had fertile sperm in store when they arrived at the carcass. Previous studies on $N$. vespilloides have shown that all reproductively active males use two alternative mate-finding tactics: (1) search for carcasses that serve as oviposition sites or (2) attract mates via pheromone emission without a carcass (Pukowski 1933; Müller and Eggert 1987; Eggert and Müller 1989). Females readily mate with pheromone-emitting males (Müller and Eggert 1987; Eggert and Müller 1989). Males of $N$. quadripunctatus also use two alternative mate-finding tactics throughout the active seasons (Takata, unpublished study). Therefore, although we collected adult beetles in only one season, October, it is likely that the high level of sperm storage in the field remains constant throughout the breeding season. Therefore, nursing males need to ensure paternity by improving their competitive ability for fertilization against previously mated males. In this study, nursing males assured a very high level of paternity. In 7 out of 11 clutches, nursing males achieved $100 \%$ paternity. Our experimental design made conditions more advantageous for non-nursing males to sire offspring than would have been the case in wild conditions, when taking into account the number of copulations and the freshness of sperm. Non-nursing males were allowed to copulate with females over a 24-h period, and, as our observational data show, they indeed copulated with females frequently. Furthermore, the copulated females started breeding immediately after the copulatory attempt with non-nursing males. However, nursing males achieved a high level of paternity, suggesting that males can ensure a high level of paternity regardless of female mating history if they remain on the carcass with the female.

Nursing males copulate with females most frequently during the pre-oviposition period. In contrast, their copulation frequency significantly decreased after the oviposition period in which the eggs were fertilized, and, therefore, males cannot increase offspring paternity by copulation. Müller and Eggert (1989) found that high levels of paternity in nursing males coincided with the increased matings of nursing males. These findings suggest that paternity assurance in Nicrophorus is caused by repeated mating. Future studies are required to determine the proximate cause of paternity assurance.

The proportion of offspring sired by nursing males was not significantly affected by hatching time (i.e. the point in time when each larva hatched). These data indicate that paternity of 2 groups of males remained constant across hatching time within a brood. A previous study revealed that offspring that hatch later face higher mortality risks when cared for by male parents (Takata, unpublished study). Therefore, if filial cannibalism by male parents plays a role in increasing the paternity of offspring, the hatching of offspring sired by nursing males would skew toward an earlier hatching period. However, our data do not support this prediction. Nursing males assured very high levels of paternity (i.e. $100 \%$ paternity in 7/11 clutches). Furthermore, paternity of 2 groups of males remained constant across hatching time within a brood. These results suggest that male parents of $N$. quadripunctatus do not increase their paternity share through filial cannibalism.

In conclusion, we found that nursing males assure a very high level of paternity of hatching offspring. We also found that the paternity of 2 groups of males remained constant across hatching time within a brood, indicating that it is unlikely that filial cannibalism plays a role in increasing the paternity of the offspring. Our study shows that, in 
N. quadripunctatus, ensuring paternity before fertilization is more important in increasing the paternity of offspring than filial cannibalism after fertilization.

Acknowledgments This study was supported by Grant-in-Aid for Scientific Research (B:23300281) from The Ministry of Education, Culture, Sports, Science and Technology (MEXT) to H.F. We are very grateful to two anonymous referees for providing valuable suggestions that greatly improved the manuscript.

\section{References}

Bateman AJ (1948) Intra-sexual selection in Drosophila. Heredity 2:349-368

Bates D, Maechler M (2010): lme4: Linear mixed-effects models using S4 classes. R package version 0.999375-37. http://CRAN. R-project.org/package $=$ lme4

Beck CW (1998) Mode of fertilization and parental care in anurans. Anim Behav 55:439-449

Clutton-Brock TH (1991) The evolution of parental care. Princeton University Press, Princeton

Cockburn A (2006) Prevalence of different modes of parental care in birds.Proc R Soc Lond B 273:1375-1383

Crawford LA, Koscinski D, Keyghobadi N (2012) A call for more transparent reporting of error rates: the quality of AFLP data in ecological and evolutionary research. Mol Ecol 21:5911-5917

Davies NB (1992) Dunnock behavior and social evolution. Oxford University Press, Oxford

Eggert A-K, Müller JK (1989) Pheromone-mediated attraction in burying beetles. Ecol Entomol 14:235-237

Eggert A-K, Müller JK (1997) Biparental care and social evolution in burying beetles: lessons from the larder. In: Choe JE, Crespi BJ (eds) The evolution of social behavior in insects and arachnids. Cambridge University Press, Cambridge, pp 216-236

Eggert A-K, Reinking M, Müller JK (1998) Parental care improves offspring survival and growth in burying beetles. Anim Behav 55:97-107

FitzGerald GJ (1992) Filial cannibalism in fishes: why do parents eat their offspring? Trends Ecol Evol 7:7-10

García-González F, Nüñez Y, Ponz F, Roldán ERS, Gomendio M (2003) Sperm competition mechanisms, confidence of paternity, and the evolution of paternal care in the golden egg bug (Phyllomorpha laciniata). Evolution 57:1078-1088

García-González F, Nüñez Y, Ponz F, Roldán ERS, Gomendio M (2005) Paternity analysis in the golden egg bug using AFLPs: do the males preferentially accept their true genetic offspring? Ecol Entomol 30:444-455

Manica A (2002) Filial cannibalism in teleost fish. Biol Rev 77: 261-277

Müller JK, Eggert A-K (1987) Effects of carrion-independent pheromone emission by male burying beetles (Silphidae: Nicrophorus). Ethology 76:297-304

Müller JK, Eggert A-K (1989) Paternity assurance by "helpful" males: adaptations to sperm competition in burying beetles. Behav Ecol Sociobiol 24:245-249
Müller JK, Eggert A-K (1990) Time-dependent shifts between infanticidal and parental behavior in female burying beetles-a mechanism of indirect mother-offspring recognition. Behav Ecol Sociobiol 27:11-16

Parker GA (1970) Sperm competition and its evolutionary consequences in the insects. Biol Rev 45:525-567

Pompanon F, Bonin A, Bellemain E, Taberlet P (2005) Genotyping errors: causes, consequences and solutions. Nat Rev Genetics 6:847-856

Pukowski E (1933) Okologische Untersuchungen an Necrophorus F. Z Morphol Oekol Tiere 27:518-586

Questiau S, Eybert MC, Taberlet P (1999) Amplified fragment length polymorphism (AFLP) markers reveal extra-pair parentage in a bird species: the bluethroat (Luscinia svecica). Mol Ecol 8:1331-1339

Reynolds JD, Goodwin NB, Freckleton RP (2002) Evolutionary transitions in parental care and live bearing in vertebrates. Proc R Soc Lond B 357:269-281

Scott MP (1998) The ecology and behavior of burying beetles. Annu Rev Entomol 43:595-618

Scott MP, Williams SM (1993) Comparative reproductive success of communally breeding burying beetles as assessed by PCR with randomly amplified polymorphic DNA. Proc Natl Acad Sci USA 90:2242-2245

Simmons LW, Beveridge M, Krauss S (2004) Genetic analysis of parentage within experimental populations of a male dimorphic beetle, Onthophagus taurus, using amplified fragment length polymorphism. Behav Ecol Sociobiol 57:164-173

Smiseth PT, Moore AJ (2002) Does resource availability affect off spring begging and parental provisioning in a partially begging species? Anim Behav 63:577-585

Smiseth PT, Darwell CT, Moore AJ (2003) Partial begging: an empirical model for the early evolution of offspring signalling. Proc R Soc Lond B 270:1773-1777

Summers K, McKeon CS, Heying H (2006) The evolution of parental care and egg size: a comparative analysis in frogs. Proc R Soc Lond B 273:687-692

Suzuki S, Nagano M, Kobayashi N (2006) Mating competition and parentage assessment in Ptomascopus morio (Coleoptera: Silphidae): a case for resource defense polygyny. Eur J Entomol 103:751-755

Tallamy DW (2000) Sexual selection and the evolution of exclusive paternal care in arthropods. Anim Behav 60:559-567

Trumbo ST, Fiore AJ (1991) A genetic marker for investigating paternity and maternity in the burying beetle Nicrophorus orbicollis (Coleoptera: Silphidae). J NY Entomol Soc 99:637642

Vos P, Hogers R, Bleeker M, Reijans M, Lee T, Hornes M, Friters A, Pot J, Paleman J, Kuiper M, Zabeau M (1995) AFLP: a new technique for DNA fingerprinting. Nucleic Acids Res 23:44074414

Wedell N, Kvarnemo C, Lessells CKM, Tregenza T (2006) Sexual conflict and life histories. Anim Behav 71:999-1011

Zar JH (1984) Biostatistical analysis. Prentice-Hall, Englewood Cliffs

Zeh DW, Smith RL (1985) Paternal investment by terrestrial arthropods. Am Zool 25:785-805 